\title{
Selective cytotoxicity of indirect nonequilibrium atmospheric pressure plasma against ovarian clear-cell carcinoma
}

\author{
Fumi Utsumi ${ }^{1}$, Hiroaki Kajiyama ${ }^{*}$, Kae Nakamura ${ }^{1}$, Hiromasa Tanaka ${ }^{2}$, Masaru Hori $^{2}$ and Fumitaka Kikkawa ${ }^{1}$
}

\begin{abstract}
Ovarian clear cell carcinoma (CCC) is a histological type of epithelial ovarian cancer that is less responsive to chemotherapy and associated with a poorer prognosis than serous and endometrioid carcinoma. Non-thermal atmospheric pressure plasma which produces reactive species has recently led to an explosion of research in plasma medicine. Plasma treatment can be applied to cancer treatment to induce apoptosis and tumor growth arrest. Furthermore, recent studies have shown that a medium exposed to plasma also has an anti-proliferative effect against cancer in the absence of direct exposure to plasma. In this study, we confirmed whether this indirect plasma has an anti-tumor effect against CCC, and investigated whether this efficacy is selective for cancer cells. Non-thermal atmospheric pressure plasma induced apoptosis in CCC cells, while human peritoneal mesothelial cells remained viable. Non-thermal atmospheric pressure plasma exhibits selective cytotoxicity against CCC cells which are resistant to chemotherapy.
\end{abstract}

Keywords: Nonequilibrium atmospheric pressure plasma; Epithelial ovarian cancer (EOC); Clear-cell carcinoma; Chemoresistance; Apoptosis; Selective cytotoxicity

\section{Background}

Epithelial ovarian carcinoma (EOC) is the most frequent cause of gynecological cancer-related death in women in Western countries. Ovarian clear-cell carcinoma (CCC), a subtype of EOC, is relatively less sensitive to chemotherapy, and is therefore recognized as refractory ovarian cancer (Kajiyama et al. 2012). Even though a combination of carboplatin and paclitaxel have been established as standard therapy for ovarian cancer (McGuire et al. 1996), CCC shows lower response rates (Itamochi et al. 2008; Anglesio et al. 2011), while serous adenocarcinoma and endometrioid adenocarcinoma respond well to this regimen. Moreover, the incidence of CCC has been increasing, and it is now estimated to be more than $20 \%$ in Japan, whereas that in Europe is reportedly 5-6\% (Anglesio et al. 2011). Although various additional molecular-targeting therapies, including antiangiogenic agents and cancer vaccine treatment, have

\footnotetext{
* Correspondence: kajiyama@med.nagoya-u.ac.jp

'Department of Obstetrics and Gynecology, Nagoya University Graduate School of Medicine, Tsuruma-cho 65, Showa-ku, Nagoya 466-8550, Japan Full list of author information is available at the end of the article
}

been investigated in order to overcome such chemoresistance, the effect of such treatment is not satisfactory, and no treatment has been established for this histological subtype of EOC.

Plasma is defined as ionized gas containing energy particles including electrons, ions, neutral atoms, and molecules such as free radicals and electronically excited atoms. Since it has become possible to generate plasma at room temperature and atmospheric pressure due to the technical developments, plasma has been gaining interest in medical field as well as industrial fields. In medical field plasma has been studied and applied for sterilization (Klampfl et al. 2012), implants (Coelho et al. 2012), blood coagulation (Bergler et al. 2001), and wound healing (Isbary et al. 2012). Additionally, it had been demonstrated that plasma can induce apoptosis in cancerous cells (Fridman et al. 2007; Keidar et al. 2011; Kim et al. 2010a; Kalghatgi et al. 2011), and it is expected to provide an alternative for cancer treatment. What is required for anti-neoplastic agents is to have selective cytotoxicity against cancer cells with minimized side effects on normal cells and have appropriate drug 
delivery system that allows the agents to reach the targeted tumor. Some researchers have reported the therapeutic potential of the selective cytotoxicity of plasma (Keidar et al. 2011; Kim et al. 2009; Tanaka et al. 2011). In our previous study, we also confirmed the selectivity of plasma against EOC (Iseki et al. 2012; Utsumi et al. 2013).

Although the mechanism behind this selective cytotoxicity of plasma is not fully understood, plasma may generate various reactive oxygen species (ROS), such as superoxide $\left(\mathrm{O}_{2}^{--}\right)$hydroxyl $\left(\mathrm{OH}^{*}\right)$, hydrogen peroxide $\left(\mathrm{H}_{2} \mathrm{O}_{2}\right)$, singlet oxygen $\left({ }^{1} \mathrm{O}_{2-}\right)$, ozone $\left(\mathrm{O}_{3}\right)$, leading to peroxidation of the lipid double membrane and resulting in apoptosis (Kalghatgi et al. 2011; Vandamme et al. 2012; Ishaq et al. 2014; Yan et al. 2012a). Cancer cells generate more intrinsic ROS than normal cells due to their high metabolic activity. Therefore, cancer cells may be more vulnerable to ROS-inducing reagents, like some chemotherapeutic drugs. Furthermore, several ROS generated by plasma have also been detected in the culture medium during exposure to plasma, called indirect plasma or plasma-activated medium, and this has been applied to cancer treatment. This method, in which cells are exposed to some liquid exposed to plasma beforehand, has been demonstrated to exhibit an anti-tumor effect comparable to direct plasma (Kalghatgi et al. 2011; Tanaka et al. 2011; Ryu et al. 2013). Considering the well-known characteristic of EOC disseminating throughout the peritoneal cavity, indirect plasma is suitable for intraperitoneal administration.

In this study, using indirect plasma in the form of nonequilibrium atmospheric pressure plasma (NEAPP), which is a type of non-thermal atmospheric pressure plasma, we demonstrated selective cytotoxicity against CCC cells, which are less sensitive to chemotherapy compared to normal cells. Taking intraperitoneal administration into account, we used human omental peritoneal mesothelial cells as normal cells.

\section{Results}

\section{Effect of NEAPP-AM on clear cell carcinoma cell line}

We first evaluated the anti-tumor effect of NEAPP-AM on the growth of the CCC cell line using the cell viability assay. Figure 1 shows the cell viability of TOV21G cells exposed to NEAPP-AM for $24 \mathrm{hrs}$, which was prepared beforehand by exposure to NEAPP for the indicated time. The viability decreased by approximately $61 \%$ when cells were treated with NEAPP-AM-5, and $87 \%$ after being treated with NEAPP-AM-8 compared to non-NEAPPexposed medium treatment $(P<0.01)$. These findings suggest that the NEAPP-AM treatment also has an anti-tumor effect on CCC cells. Furthermore, we confirmed the antitumor effect of NEAPP-AM on other EOC cell lines (ES-2, SKOV3, and NOS2). Figure 2 shows the cell viabilities of these cells exposed to NEAPP-AM-8 for $24 \mathrm{hrs}$. Significant cytotoxicity was demonstrated in every EOC cell line.

\section{Morphological changes observed in EOC cell lines induced by NEAPP-AM}

Morphological investigations of EOC cells exposed to NEAPP-AM were performed. Images of untreated EOC cells are shown in (Figure 3A). The cells treated with NEAPP-AM (15) -5 were observed 6 hrs after treatment and displayed changes, such as shrinking, rounding up, and detachment from dishes which were typical of apoptosis (Figure 3B).

\section{Role of ROS and attenuated and enhanced NEAPP-AM effect with NAC and BSO}

Subsequently, we examined whether ROS produced by NEAPP are responsible for the anti-tumor effects on CCC cells as well as serous EOC cells in tests we previously performed. To investigate the role of ROS in NEAPP-AM treatment, TOV21G cells were pre-incubated with NAC or BSO, followed by the addition of NEAPP-AM for the indicated exposure times. The viability of TOV21G cells was assayed 24 hrs after NEAPP-AM treatment using the cell viability assay. As shown in Figure 4, the growth-inhibitory effects of NEAPP-AM were completely blocked on being pretreatment and co-incubation with NAC (Figure 4A). In contrast, BSO (Figure 4B) with NEAPP-AM decreased cell viability; especially, BSO with NEAPP-AM-1, -3 led to a significant decrease, compared to the control (NEAPP-AM treatment alone) $(P<0.01)$. These results suggest that ROS in cells produced by NEAPP-AM play a critical role in anti-tumor effects against EOC cells.

\section{NEAPP-AM-induced apoptosis in TOV21G and SKOV3}

Subsequently, we assessed whether the cytotoxic effect of NEAPP-AM against TOV21G and SKOV3 was associated with the induction of apoptosis by TUNEL assay. To identify inner nucleosomal DNA strand breaks, a characteristic feature of apoptosis, TUNEL staining was performed at $4 \mathrm{hrs}$ after NEAPP-AM, treatment, as described in Materials and Methods. Compared with control cells, both TOV21G and SKOV3 cells treated with NEAPP-AM showed more TUNEL-positive staining cells, indicating that NEAPP-AM induced apoptosis in both cell lines (Figure 5).

\section{Selective cytotoxic effect of NEAPP-AM on TOV21G cells compared with OHFC and HPMC}

We finally examined whether NEAPP-AM has a selective anti-proliferative effect on cancer cells without causing adverse reactions in normal cells. TOV21G, OHFC, and HPMC cells were exposed to NEAPP-AM (25)-8 for $24 \mathrm{hrs}$ and investigated with cell viability assay. As shown in 


\section{TOV21G}

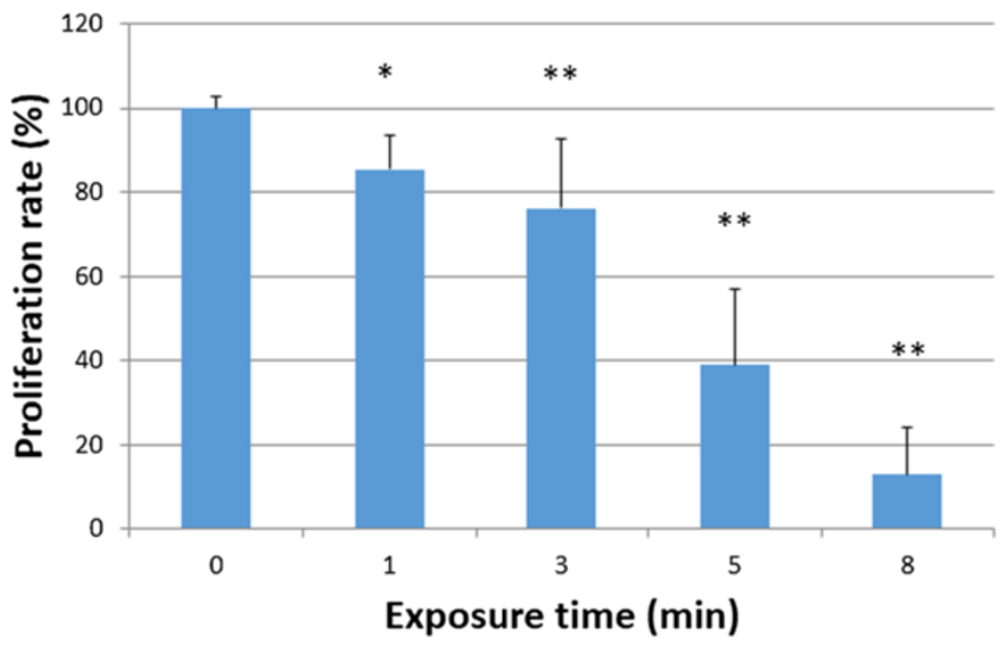

Figure 1 The effect of NEAPP-AM on cell viability. Viability of TOV21G ovarian clear cell carcinoma cells treated with NEAPP-activated medium (NEAPP-AM), as measured by the cell viability assay. TOV21G cells were plated in 96-well plates and incubated at $37^{\circ} \mathrm{C}$ with $5 \% \mathrm{CO} 2$. After 24 hrs, the culture medium was replaced with NEAPP-AM and the cells were incubated for another 24 hrs. The cell proliferation rate was evaluated relative to the control with the cell viability assay. Each column represents the mean, and the bars show SD. Assays were performed in triplicate. ${ }^{*} \mathrm{P}<0.05,{ }^{* *} \mathrm{P}<0.01$ versus control.

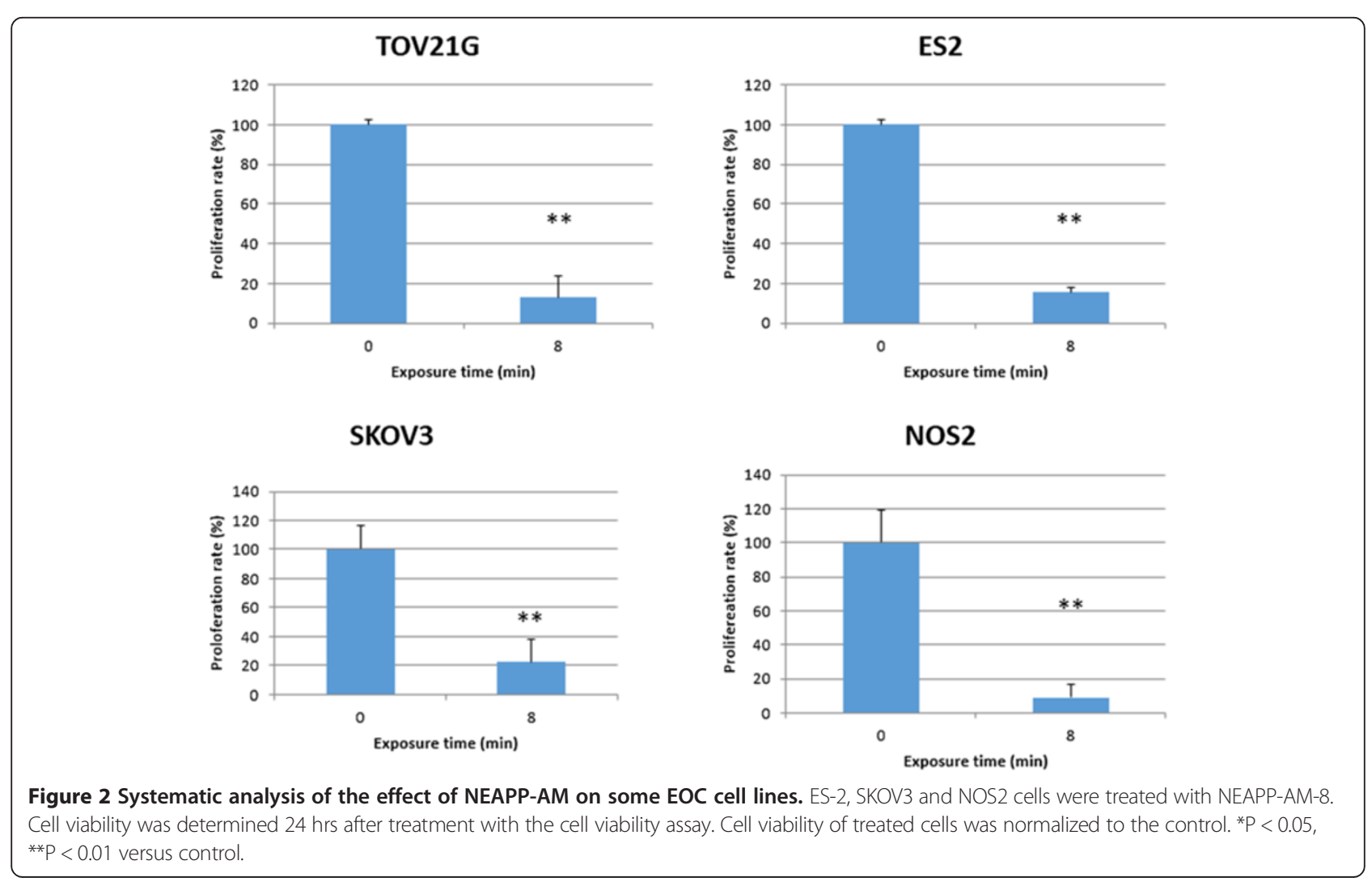


(A)
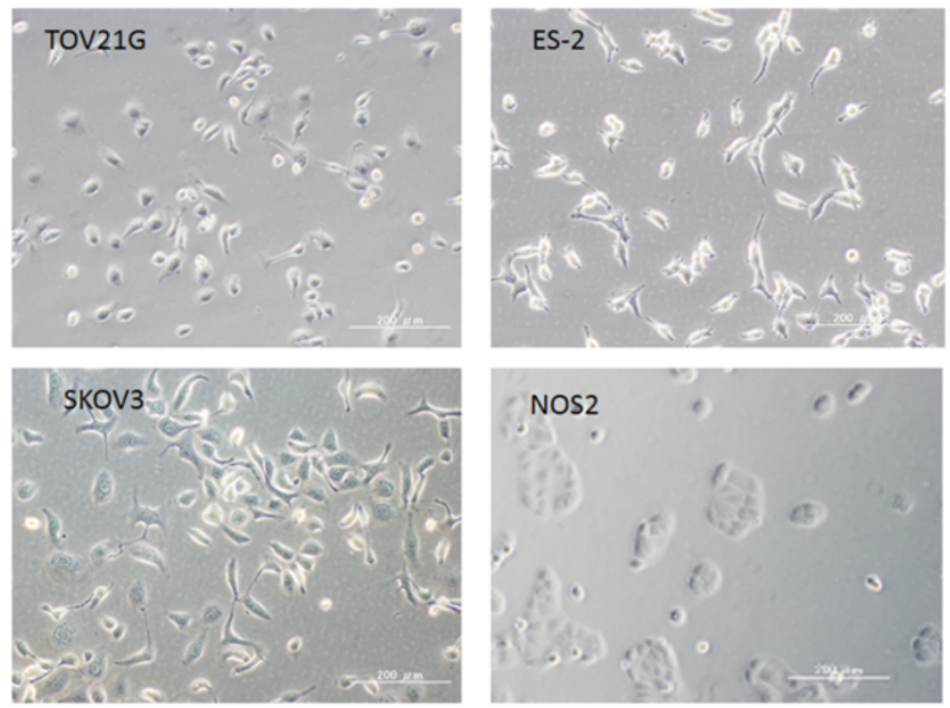

(B)
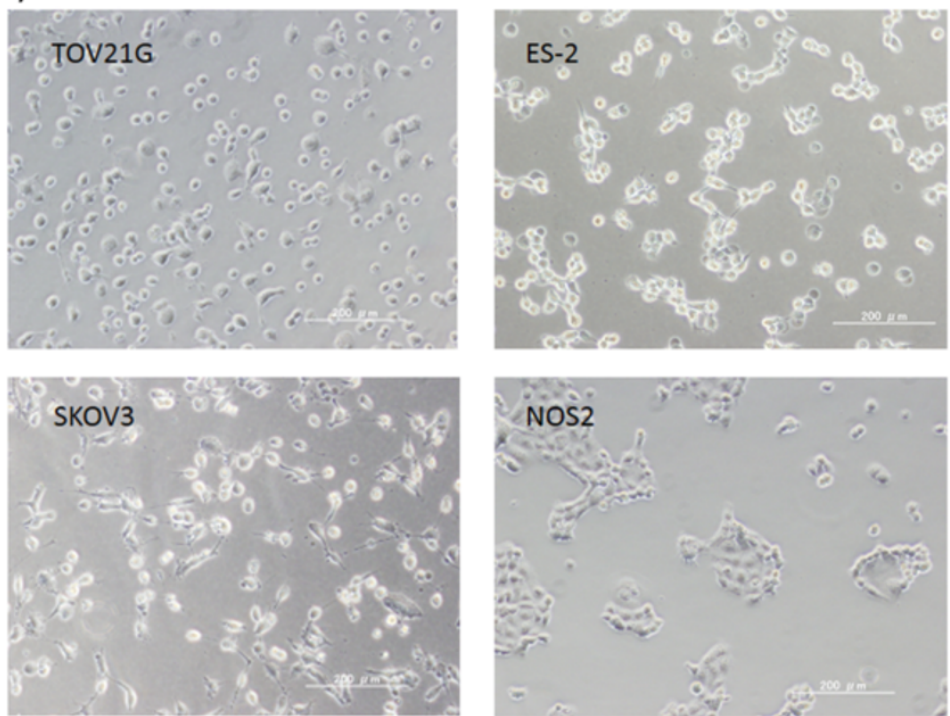

Figure 3 The morphological changes of EOC cells after NEAPP-AM treatment. A: Representative images of untreated EOC cells (TOV21G, ES-2, SKOV3, and NOS2). B: EOC cells (TOV21G, ES-2, SKOV3, and NOS2) treated with NEAPP-AM for 6 hrs.

Figure 6, the viabilities of TOV21G, OHFC, and HPMC after being treated with NEAPP-AM were 29, 100, and $71 \%$, respectively [OHFC vs. TOV21G $(P<0.01)$ : HPMC vs. TOV21G $(P<0.01)$. Remarkably, the cytotoxic effects of NEAPP-AM on normal human peritoneal cells are less sensitive than on cancer cells.

\section{Discussion}

Plasma has been used for a long time for industrial purposes. Recently, with the rapid advancement of devices that can generate plasma at atmospheric pressure, plasma has received much attention in medical fields.
Many researchers have demonstrated plasma-induced apoptosis in cancer cells (Fridman et al. 2007; Yan et al. 2012b; Kim et al. 2010b), and some of them have applied this treatment to in vivo studies (Keidar et al. 2011; Vandamme et al. 2012; Vandamme et al. 2010). Although these studies have indicated plasma treatment also has anti-tumor effects in vivo, the application is often limited to skin cancer or a xenografted model because of the characteristics of the device. When direct plasma was applied to an intraperitoneal tumor, the treatment became very invasive, involving an abdominal operation (Brulle et al. 2012). So, we have been focusing on 


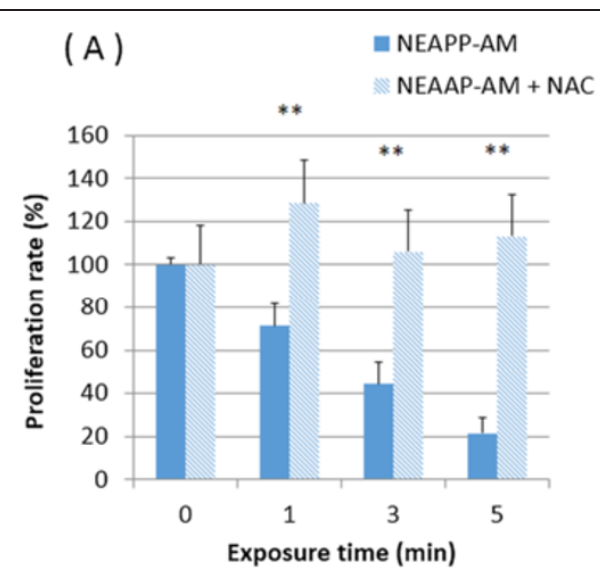

\section{(B)}

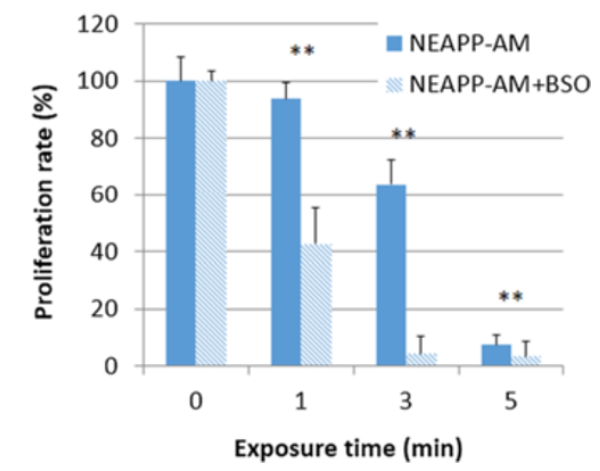

Figure 4 Role of ROS and attenuated and enhanced NEAPP-AM sensitivity with NAC and BSO. $A, B$ : Influence of intracellular ROS modulation by NAC and BSO on NEAPP-AM-induced cell death. A: TOV21G cells were pretreated with NAC (4 mM) (A) or BSO (2 mM) (B) for $1 \mathrm{hr}$ and then exposed to NEAPP-AM with NAC or BSO for an additional $24 \mathrm{hrs}$. The cell viability assay was used for evaluation. Each column represents the mean and the bars are SD. Data are representative of at least three independent experiments. ${ }^{*} P<0.05$, ${ }^{* *} P<0.01$ versus control without NAC treatment.

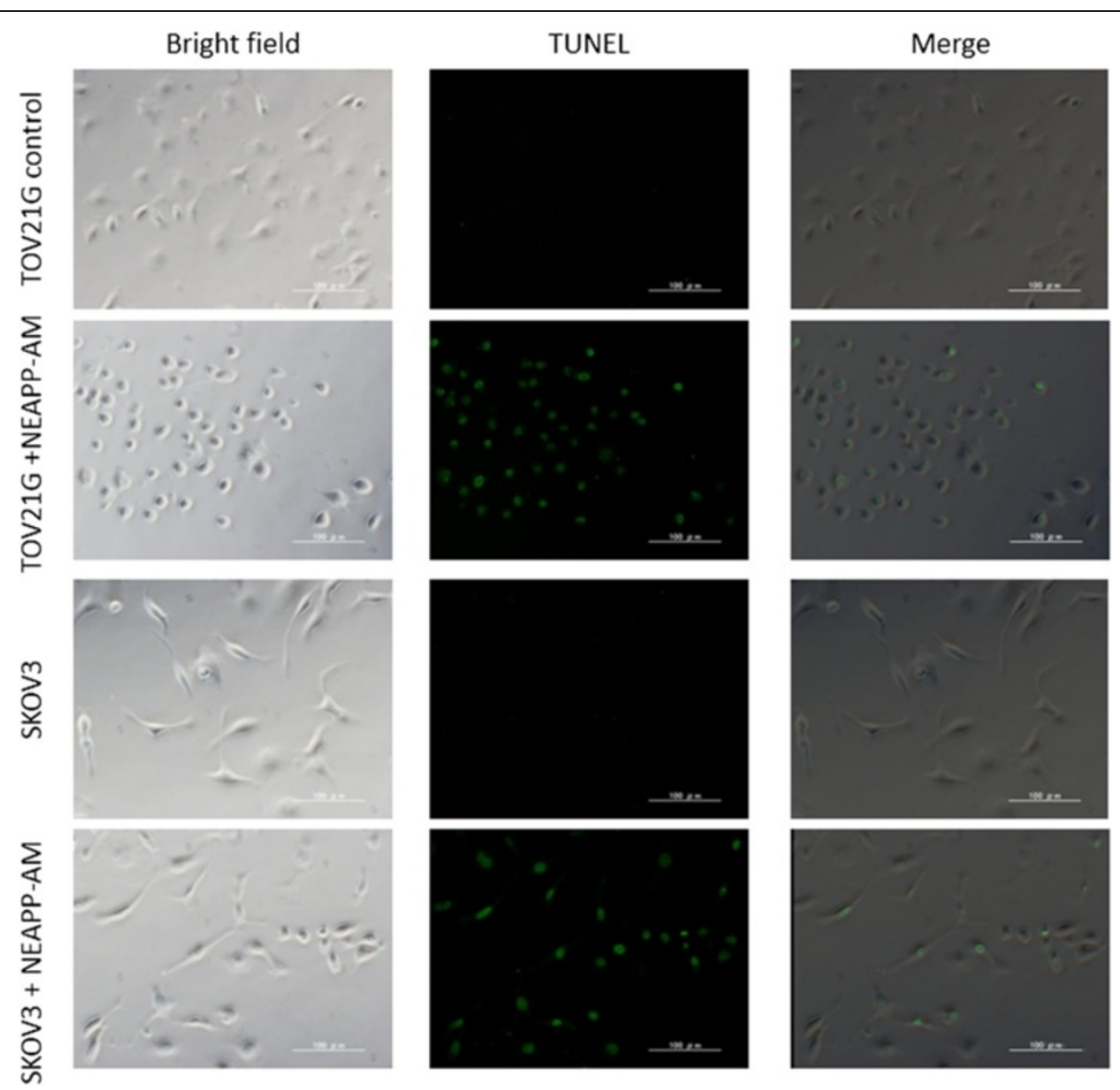

Figure 5 TUNEL assay. The TUNEL assay was performed to detect apoptosis in TOV21G and SKOV3 cells induced by NEAPP-AM. TOV21G and SKOV3 cells were treated with NEAPP-AM or control medium. Cells were incubated for 4 hrs, then fixed, and the TUNEL assay was performed. 


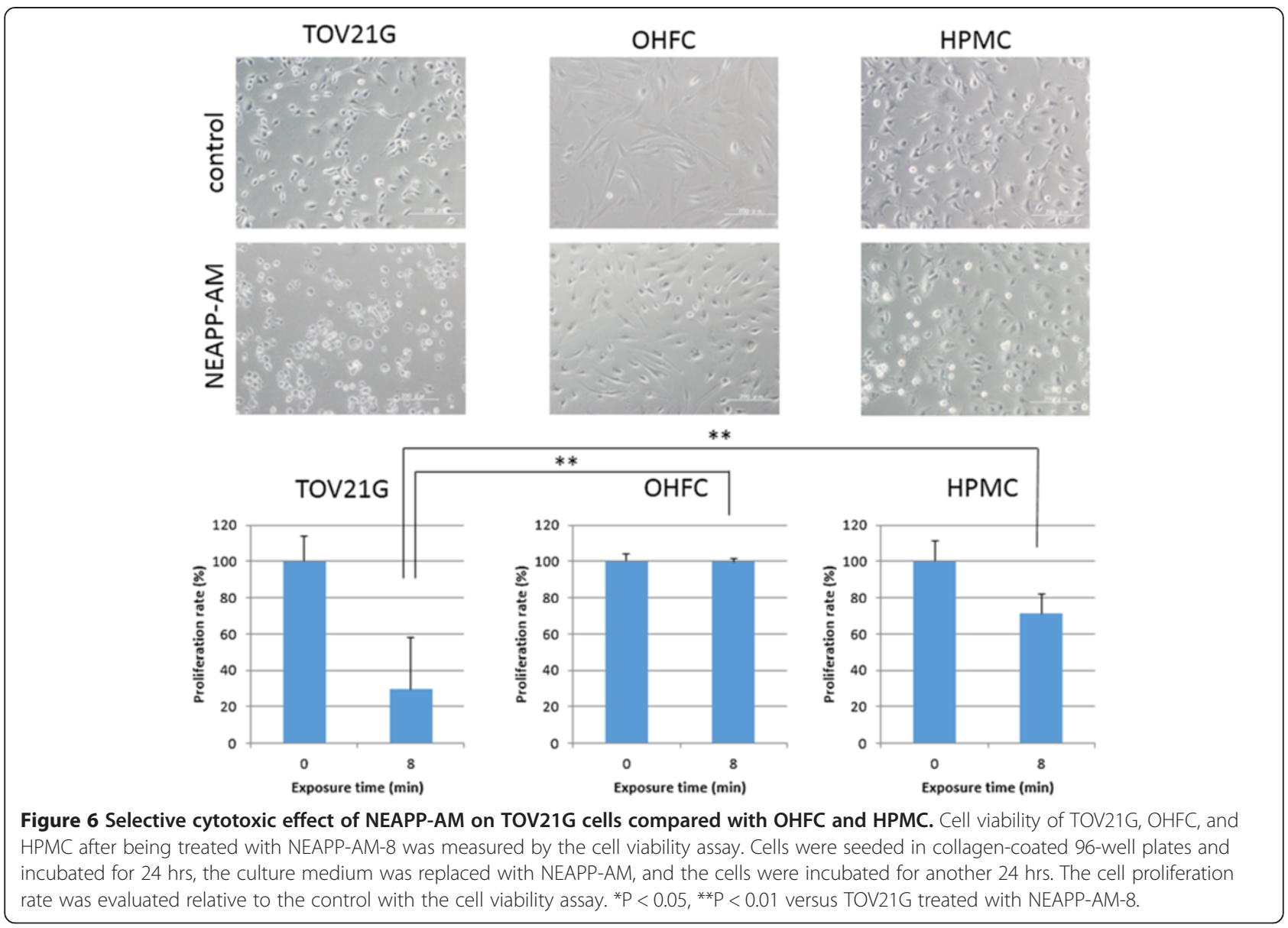

the indirect effect of plasma using NEAPP-AM in order to administer plasma for ovarian cancer as safely as possible. ROS or reactive nitrogen species generated by plasma have been shown to be transferred to the medium and exert anti-tumor effect comparable to direct plasma (Kalghatgi et al. 2011; Yan et al. 2012a; Ryu et al. 2013). We recently reported the anti-proliferative effects of NEAPP-AM against chemoresistant EOC cell lines derived from serous EOC cells in vitro and in vivo in a xenografted model (Utsumi et al. 2013). In this study, we used a CCC cell line which is naturally chemoresistant and often associated with a poor prognosis. Our experiments demonstrated a selective cytotoxic effect of NEAPP-AM on CCC, compared with normal human cells. Furthermore, the majority of patients with EOC have advanced intraperitoneal metastasis and dissemination at the time of diagnosis. Since it is important to target these disseminations without damaging surrounding normal cells, we selected peritoneal mesothelial and fibroblastic cells as normal cells.

Several mechanisms involved in drug resistance of CCC have been proposed, including decreased drug accumulation, increased drug detoxification, and increased DNA repair activity. However, the details underlying CCC's resistance to chemotherapy have not been clarified. Itamochi et al. suggested that the lower tumor proliferation may contribute to its resistance to chemotherapy (Itamochi et al. 2008). Genetically, glutathione peroxidase (GPx3), glutaredoxin $(G L R X)$, and superoxide dismutase (SOD2) were highly expressed in CCC tumors, and high levels of these antioxidant proteins may be associated, in part, with the chemoresistant phenotype of CCC (Schwartz et al. 2002). On the other hand, the anti-tumor effect of plasma has been suggested to be triggered through lipid peroxidation with an excessive amount of ROS generated by plasma. Apoptosis caused by lipid peroxidation has been related to the activity of p53, which is known as a tumor suppressor triggering cell-cycle arrest and apoptosis (Yan et al. 2012a; Tsuzuki et al. 2007). Xu Yan et al. examined mRNA expression, and revealed that cyclin B1 and Cdc2 are decreased at the transcriptional level after plasma treatment, while the expression of p21 Cdk inhibitor, as well as that of tumor suppressor p53, is enhanced (Yan et al. 2012b). This mechanical difference between chemotherapy and plasma treatment may contribute to the antiproliferative effect of plasma against CCC.

Although, plasma may be successfully used for superficial lesions, including the stimulation of wound healing, sterilization of medical instruments, and removal of 
microscopic residual cancer, regarding the use of atmospheric pressure plasma as a treatment for cancer patients, there may be some limitations such as a lack of the infiltrating capability of plasma. The depth that can be penetrated by plasma is thought to be limited. We are trying to apply NEAPP-AM treatment to intraperitoneal micro dissemination which is difficult to control with conventional treatments.

\section{Conclusion}

In conclusion our results suggest that NEAPP-AM can induce apoptosis in CCC while normal cells are less damaged. These findings indicate the possibility of being able to apply this technical modality intraperitoneally, and we are now trying to apply NEAPP-AM to I.P. therapy on a murine peritoneal metastasis model with EOCs including chemoresistant cells. NEAPP-AM may be a promising new alternative for chemoresistant EOC treatment.

\section{Methods}

\section{Cell culture}

We used four ovarian cancer cell lines involving omentumderived human fibroblastic cells (OHFC) and human peritoneal mesothelial cells (HPMC). TOV21G, ES-2, and SKOV3 were purchased from the American Tissue Culture Collection. The NOS2 cells, derived from serous EOC, were established in our institute. We described the details in our previous reports (Kajiyama et al. 2007a). OHFC and HPMC were isolated from pieces of human omentum. The tissues were obtained from consenting patients undergoing abdominal surgery at our institute (Kajiyama et al. 2007b). The study was approved by the institutional ethics committee (Approval number: 1234, Ethics Committee of Nagoya University). All cell lines were maintained in RPMI-1640 (Sigma, St. Louis, MO, USA) supplemented with $10 \%$ fetal bovine serum (FBS) and penicillin-streptomycin at $37^{\circ} \mathrm{C}$ in a humidified atmosphere of $5 \% \mathrm{CO}_{2}$.

\section{Experimental system specification and production of nonequilibrium atmospheric pressure plasma-activated medium (NEAPP-AM)}

The details of this experimental NEAPP system were previously described (Iseki et al. 2012). Discharge conditions were in argon gas (2 standard liters/ min; slm) excited by applying $10 \mathrm{kV}$ of a $60-\mathrm{Hz}$ commercial power supply to two electrodes with a distance of $8 \mathrm{~mm}$. In brief, NEAPP with an ultra-high electron density (approximately $2 \times$ $10^{16} \mathrm{~cm}^{-3}$ ) was provided with an ultra-high $\mathrm{O}$ density estimated at around $4 \times 10^{15} \mathrm{~cm}^{-3}$ (Iseki et al. 2012). Furthermore, the generation of ROS, such as hydroxyl radicals, singlet oxygen radicals, nitrogen oxide, and nitrogen, was confirmed by optical emission spectroscopy. We exposed the above NEAPP to RPMI-1640 without FBS separately from the cells, which is designated as 'nonequilibrium atmospheric pressure plasma-activated medium (NEAPPAM)'. A schema of this procedure is shown in Figure 7. The separated distance between the plasma source and medium ( $\mathrm{L}$ ) is critical to reproduce consistent data, so all experiments were performed under two set conditions: $\mathrm{L}=15$ and $25 \mathrm{~mm}$, indicated as NEAPP-AM (15) and NEAPP-AM (25), respectively. The cytotoxic effect of NEAPP-AM (15) was suggested to be stronger than NEAPP-AM (25). NEAPP-AM (25) was used for cell viability assays, while NEAPP-AM (15) was used for cell imaging assays. The duration of plasma treatment ranged from 0 to 8 minutes. Six milliliters of RPMI-1640 medium was placed in a $60-\mathrm{mm}$ dish. The center of each $60-\mathrm{mm}$ dish was treated several times $(1,3,5$, and $8 \mathrm{~min})$ with NEAPP fixed above the dish at a single point, referred to as NEAPP-AM-1, $-3,-5$, and -8 , respectively. NEAPP exposure can cause changes to media in $\mathrm{pH}$ or temperature. We have referred to them in our previous manuscript and they were almost negligible (Iseki et al. 2012). ROS in medium were generated homogeneously due to the convective flow by gas or sufficient immixture before the addition to cells.

\section{Cell viability assay}

The effect of NEAPP-AM on the viability of cells was measured with the Aqueous One Solution Cell Proliferation Assay kit (Promega, Madison, WI, USA), according to the manufacturer's instructions. Absorbance was then measured at $490 \mathrm{~nm}$ with a microplate absorbance reader (ELx808; Bio Tek, U.S.A.). The cells were plated in 96 -well plates at a density of $1 \times 10^{4}$ cells per well in $100 \mu \mathrm{L}$ of complete culture medium. When the assay

Scheme of NEAPP-AM preparation

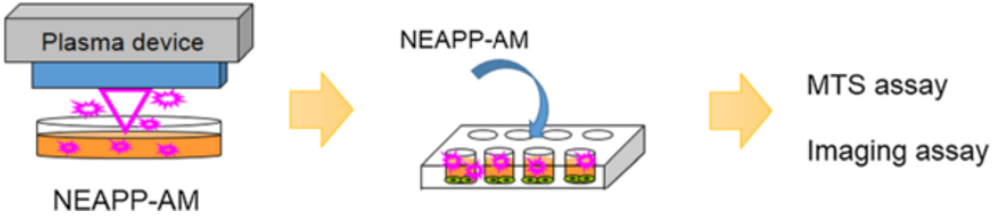

Figure 7 Scheme of procedure to produce nonequilibrium atmospheric pressure plasma-activated medium. 
included OHFC or HPMC, collagen-coated plates were used for all cell lines. The next day, cells were treated with NEAPP-AM (25) (1-8 min/6 mL) for 24 hrs. Experiments were performed in triplicate.

The influence of modulation of reactive oxidative species (ROS) by $\mathrm{N}$-acetyl cysteine and L-buthionine-[S, R]-sulfoximine $\mathrm{N}$-acetyl cysteine (NAC, Sigma-Ardrich, St. Louis, MO, USA), known as an intracellular ROS scavenger, was used to attenuate the effect of ROS. Alternatively, L-buthionine-[S, R]-sulfoximine (BSO, Sigma-Aldrich, St. Louis, MO, USA), an inhibitor of GSH synthesis, was used to enhance the effect of ROS. It is known that GSH is one of the most abundant and effective components of the defense system against free radicals, including ROS (Jefferies et al. 2003). The compounds NAC and BSO were added to cells at a final concentration of 4 and $2 \mathrm{mM}$, respectively. The required volume of each drug was added directly to complete the cell culture medium $1 \mathrm{hrs}$ before NEAPP-AM treatment and NEAPP-AM to achieve the desired final concentrations, respectively. Cell viability was examined with the "cell viability assay".

\section{TUNEL assay}

Apoptotic cells were identified using the In Situ Cell Death Detection Kit, Fluorescein (Roche Applied Science, Mannheim, Germany), according to the manufacturer's instructions. TOV21G and SKOV3 cells $\left(2 \times 10^{4} /\right.$ well $)$ were seeded in a collagen-coated 8 -well cover glass, incubated for $24 \mathrm{hrs}$, and then treated with NEAPP-AM (15)-5 or serum-free medium as a control. After 4 hrs of incubation, cells were fixed with $4 \%$ paraformaldehyde and the TUNEL reaction mixture was added. After being incubated in a chamber for $60 \mathrm{~min}$ at $37^{\circ} \mathrm{C}$, cells were observed with a fluorescence microscope. This experiment was repeated at least three times.

\section{Statistical analysis}

Data are presented as means \pm SD from at least three independent experiments. Statistical analysis of the data between two gropes was performed using Student's $t$-test and statistical analysis between more than two gropes was performed by Dunnett's test or Tukey-Kramer test Differences between groups were considered significant at $P<0.05$.

\section{Abbreviations}

EOC: Epithelial ovarian cancer; CCC: Ovarian clear cell carcinoma; ROS: Reactive oxygen species; NEAPP: Nonequilibrium atmospheric pressure plasma; OHFC: Omentum-derived human fibroblastic cells; HMPC: Human peritoneal mesothelial cells; FBS: Fetal bovine serum; NEAPP-AM: Nonequilibrium atmospheric pressure plasma-activated medium; GPx3: Glutathione peroxidase; GLRX: Glutaredoxin; SOD2: Superoxide dismutase.
Competing interests

The authors declare that they have no competing interests.

\section{Authors' contributions}

FU carried out the experimental studies, performed the statistical analysis and participated in the drafting the manuscript. HK conceived of the study, and participated in its design and helped to draft the manuscript. KN participated in the experimental studies. HT participated in the analysis of plasma generating devise. $\mathrm{MH}$ set up the plasma generating devise and carried out the analysis of it. FK participated in the design of the study and coordination. All authors read and approved the final manuscript.

\section{Acknowledgements}

The authors are grateful to Mr. Hiroyuki Kano for preparing the NEAPP-AMgenerating device.

\section{Author details}

'Department of Obstetrics and Gynecology, Nagoya University Graduate School of Medicine, Tsuruma-cho 65, Showa-ku, Nagoya 466-8550, Japan. ${ }^{2}$ Department of Electrical Engineering and Computer Science, Graduate School of Engineering, Nagoya University, Furo-cho, Chikusa-ku, Nagoya 464-8603, Japan.

Received: 2 May 2014 Accepted: 8 July 2014

Published: 31 July 2014

\section{References}

Anglesio MS, Carey MS, Kobel M, Mackay H, Huntsman DG, Vancouver Ovarian Clear Cell Symposium Speakers (2011) Clear cell carcinoma of the ovary: a report from the first Ovarian Clear Cell Symposium, June 24th, 2010. Gynecol Oncol 121:407-415

Bergler W, Huber K, Hammerschmitt N, Hörmann K (2001) Tonsillectomy with argon plasma coagulation (APC): evaluation of pain and hemorrhage. Laryngoscope 111:1423-1429

Brulle L, Vandamme M, Ries D, Martel E, Robert E, Lerondel S, Trichet V, Richard S, Pouvesle JM, Le Pape A (2012) Effects of a non thermal plasma treatment alone or in combination with gemcitabine in a MIA PaCa2-luc orthotopic pancreatic carcinoma model. PLoS One 7:e52653

Coelho PG, Giro G, Teixeira HS, Marin C, Witek L, Thompson VP, Tovar N, Silva NR (2012) Argon-based atmospheric pressure plasma enhances early bone response to rough titanium surfaces. J Biomed Mater Res A 100:1901-1906

Fridman G, Shereshevsky A, Jost MM, Brooks AD, Fridman A, Gutsol A, Vasilets V, Friedman $G$ (2007) Floating electrode dielectric barrier discharge plasma in air promoting apoptotic behavior in melanoma skin cancer cell lines. Plasma Chem Plasma Process 27:163-176

Isbary G, Heinlin J, Shimizu T, Zimmermann JL, Morfill G, Schmidt HU, Monetti R, Steffes B, Bunk W, Li Y, Klaempfl T, Karrer S, Landthaler M, Stolz W (2012) Successful and safe use of 2 min cold atmospheric argon plasma in chronic wounds: results of a randomized controlled trial. Br J Dermatol 167:404-410

Iseki S, Nakamura K, Hayashi M, Tanaka H, Kondo H, Kajiyama H, Kano H, Kikkawa F, Hori M (2012) Selective killing of ovarian cancer cells through induction of apoptosis by nonequilibrium atmospheric pressure plasma. Appl Phys Lett 100:113702

Ishaq M, Evans MM, Ostrikov KK (2014) Effect of atmospheric gas plasmas on cancer cell signaling. Int J Cancer 134(7):1517-1528

Itamochi H, Kigawa J, Terakawa N (2008) Mechanisms of chemoresistance and poor prognosis in ovarian clear cell carcinoma. Cancer Sci 99:653-658

Jefferies H, Coster J, Khalil A, Bot J, McCauley RD, Hall JC (2003) Glutathione. ANZ J Surg 73:517-522

Kajiyama H, Shibata K, Terauchi M, Yamashita M, Ino K, Nawa A, Kikkawa F (2007a) Chemoresistance to paclitaxel induces epithelial-mesenchymal transition and enhances metastatic potential for epithelial ovarian carcinoma cells. Int J Oncol 31:277-283

Kajiyama H, Shibata K, Ino K, Nawa A, Mizutani S, Kikkawa F (2007b) Possible involvement of SDF-1alpha/CXCR4-DPPIV axis in TGF-beta1-induced enhancement of migratory potential in human peritoneal mesothelial cells. Cell Tissue Res 330:221-229

Kajiyama H, Shibata K, Mizuno M, Yamamoto E, Fujiwara S, Umezu T, Suzuki S, Nakanishi T, Nagasaka T, Kikkawa F (2012) Postrecurrent oncologic outcome of patients with ovarian clear cell carcinoma. Int J Gynecol Cancer 22:801-806 
Kalghatgi S, Kelly CM, Cerchar E, Torabi B, Alekseev O, Fridman A, Friedman G, Azizkhan-Clifford J (2011) Effects of non-thermal plasma on mammalian cells. PLoS One 6:e16270

Keidar M, Walk R, Shashurin A, Srinivasan P, Sandler A, Dasgupta S, Ravi R, Guerrero-Preston R, Trink B (2011) Cold plasma selectivity and the possibility of a paradigm shift in cancer therapy. Br J Cancer 105:1295-1301

Kim GC, Kim GJ, Park SR, Jeon SM, Seo HJ, Iza F, Lee JK (2009) Air plasma coupled with antibody-conjugated nanoparticles: a new weapon against cancer. J Phys D Appl Phys 42:032005

Kim SJ, Chung TH, Bae SH, Leem SH (2010a) Induction of apoptosis in human breast cancer cells by a pulsed atmospheric pressure plasma jet. Appl Phys Lett 97:023702

Kim GJ, Kim W, Kim KT, Lee JK (2010b) DNA damage and mitochondria dysfunction in cell apoptosis induced by nonthermal air plasma. Appl Phys Lett 96:021502

Klampfl TG, Isbary G, Shimizu T, Li YF, Zimmermann JL, Stolz W, Schlegel J, Morfill GE, Schmidt HU (2012) Cold atmospheric air plasma sterilization against spores and other microorganisms of clinical interest. Appl Environ Microbiol 78:5077-5082

McGuire WP, Hoskins WJ, Brady MF, Brady MF, Kucera PR, Partridge EE, Look KY, Clarke-Pearson DL, Davidson M (1996) Cyclophosphamide and cisplatin compared with paclitaxel and cisplatin in patients with stage III and stage IV ovarian cancer. N Engl J Med 334:1-6

Ryu YH, Kim YH, Lee JY, Shim GB, Uhm HS, Park G, Choi EH (2013) Effects of background fluid on the efficiency of inactivating yeast with non-thermal atmospheric pressure plasma. PLoS One 8:e66231

Schwartz DR, Kardia SL, Shedden KA, Kuick R, Michailidis G, Taylor JM, Misek DE, Wu R, Zhai Y, Darrah DM, Reed H, Ellenson LH, Giordano TJ, Fearon ER, Hanash SM, Cho KR (2002) Gene expression in ovarian cancer reflects both morphology and biological behavior, distinguishing clear cell from other poor-prognosis ovarian carcinomas. Cancer Res 62:4722-4729

Tanaka H, Mizuno M, Ishikawa K, Nakamura K, Kajiyama H, Kano H, Kikkawa F, Hori M (2011) Plasma-activated medium selectively kills glioblastoma brain tumor cells by down-regulating a survival signaling molecule, AKT kinase. Plasma Med 1:265-277

Tsuzuki T, Kambe T, Shibata A, Kawakami Y, Nakagawa K, Miyazawa T (2007) Conjugated EPA activates mutant p53 via lipid peroxidation and induces p53-dependent apoptosis in DLD-1 colorectal adenocarcinoma human cells. Biochim Biophys Acta 1771:20-30

Utsumi F, Kajiyama H, Nakamura K, Tanaka H, Mizuno M, Ishikawa K, Kondo H, Kano H, Hori M, Kikkawa F (2013) Effect of indirect nonequilibrium atmospheric pressure plasma on anti-proliferative activity against chronic chemo-resistant ovarian cancer cells in vitro and in vivo. PLoS One 8:e81576

Vandamme M, Robert E, Pesnel S, Barbosa E, Dozias S, Sobilo J, Lerondel S, Pape AL, Pouvesle J (2010) Antitumor effect of plasma treatment on U87 glioma xenografts: preliminary results. Plasma Process Polym 7:264-273

Vandamme M, Robert E, Lerondel S, Sarron V, Ries D, Dozias S, Sobilo J, Gosset D, Kieda C, Legrain B, Pouvesle JM, Pape AL (2012) ROS implication in a new antitumor strategy based on non-thermal plasma. Int J Cancer 130:2185-2194

Yan X, Xiong Z, Zou F, Zhao S, Lu X, Yang G, He G, Ostrikovet K (2012a) Plasmainduced death of HepG2 cancer cells: intracellular effects of reactive species. Plasma Process Polym 9:59-66

Yan X, Zou F, Zhao S, Lu X, He G, Xiong Z, Xiong Q, Zhao Q, Deng P, Huang J, Yanget $\mathrm{G}$ (2012b) On the mechanism of plasma inducing cell apoptosis. IEEE Trans Plasma Sci 38:2451-2457

\section{Submit your manuscript to a SpringerOpen ${ }^{\circ}$ journal and benefit from:}

- Convenient online submission

Rigorous peer review

- Immediate publication on acceptance

- Open access: articles freely available online

- High visibility within the field

- Retaining the copyright to your article

Submit your next manuscript at $>$ springeropen.com 